\title{
Interactive comment on "Late Pliocene Cordilleran Ice Sheet development with warm Northeast Pacific sea surface temperatures" by Maria Luisa Sánchez-Montes et al.
}

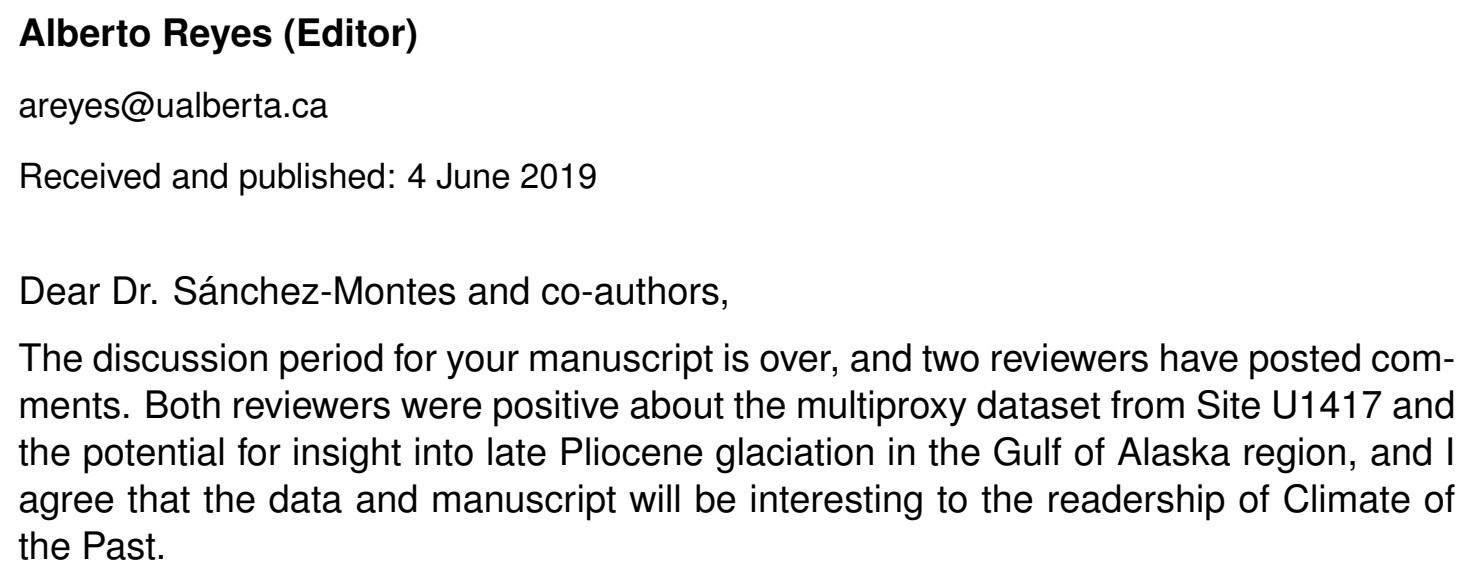

Dear Dr. Sánchez-Montes and co-authors,

The discussion period for your manuscript is over, and two reviewers have posted comments. Both reviewers were positive about the multiproxy dataset from Site U1417 and the potential for insight into late Pliocene glaciation in the Gulf of Alaska region, and I agree that the data and manuscript will be interesting to the readership of Climate of the Past.

However, there are several broad points of concern. In particular, both reviewers iden- 
tify section 4.4 as problematic with respect to clarity and whether the data support the conclusions being made. I also agree that the manuscript would benefit from additional support for the biomarker-based inferences on glaciation and some discussion of the published literature on terrestrial records of late Pliocene CIS glaciation. I think it should be possible to address these concerns with moderate-to-major revision of the manuscript.

comment

Please respond to the reviewer comments in the online Discussion forum. If you intend to make any changes to your manuscript in response to these comments, please clearly indicate the nature of these changes in your response. Once I have reviewed your response, I fully anticipate inviting you to submit a revised manuscript for further consideration.

Sincerely, Alberto Reyes

Interactive comment on Clim. Past Discuss., https://doi.org/10.5194/cp-2019-29, 2019. 